\section{Regenerating reptile retinas: a comparative approach to restoring retinal ganglion cell function}

\begin{abstract}
Transection or damage to the mammalian optic nerve generally results in loss of retinal ganglion cells by apoptosis. This cell death is seen less in fish or amphibians where retinal ganglion cell survival and axon regeneration leads to recovery of sight. Reptiles lie somewhere in the middle of this spectrum of nerve regeneration, and different species have been reported to have a significant variation in their retinal ganglion cell regenerative capacity. The ornate dragon lizard Ctenophoris ornatus exhibits a profound capacity for regeneration, whereas the Tenerife wall lizard Gallotia galloti has a more variable response to optic nerve damage. Some individuals regain visual activity such as the pupillomotor responses, whereas in others axons fail to regenerate sufficiently. Even in Ctenophoris, although the retinal ganglion cell axons regenerate adequately enough to synapse in the tectum, they do not make long-term topographic connections allowing recovery of complex visually motivated behaviour. The question then centres on where these intraspecies differences originate. Is it variation in the innate ability of retinal ganglion cells from different species to regenerate with functional validity? Or is it variances between different species in the substrate within which the nerves regenerate, the extracellular environment of the damaged nerve or the supporting cells surrounding the regenerating axons? Investigations of retinal ganglion cell regeneration between different species of lower vertebrates in vivo may shed light on these questions. Or perhaps more interesting are in vitro studies comparing axon regeneration of retinal ganglion cells from various species placed on differing substrates.
\end{abstract}

DL Williams

DLWiams

Eye (2017) 31, 167-172; doi:10.1038/eye.2016.224; published online 11 November 2016

\section{Introduction}

Have you ever wondered why the rod of Asclepius, that ancient sign of medical healing, ${ }^{1}$ is characterised by a snake entwined around a staff (Figure 1)? The healing temples of Asclepius were apparently inhabited by snakes, which crawled freely around the floors where the patients seeking healing spent the night. The snake was a sign of the duality of life and death. Often venomous to be sure, but also a sign of life renewed. The regular ecdysis or sloughing of the entire skin occurring regularly as the snake grew through life was central to this sign. As Comutus, a first century CE philosopher notes 'Asclepius derived his name from healing soothingly and from deferring the withering that comes with death. For this reason, therefore, they give him a serpent as an attribute, indicating that those who avail themselves of medical science undergo a process similar to the serpent in that they, as it were, grow young again after illnesses and slough off old age.' Pliny the Elder (23-79 CE) wrote 'The snake, when the membrane covering its body has been contracted by the cold of winter, throws it off in the spring and thus becomes sleek and youthful in appearance. The same animal, too, on finding its sight weakened during its winter retreat, anoints and refreshes its eyes by rubbing itself on the fennel plant. ${ }^{2}$ The ophidian eye is indeed covered by fused eyelids, the spectacle, which becomes opaque before it is shed with the rest of the skin as the reptile increases in size through life. Very interesting, you might say, but what has this to do with the retinal ganglion cell?
Department of Veterinary Medicine, University of Cambridge, Queen's Veterinary School Hospital, Cambridge, UK

Correspondence: DL Williams, Department of Veterinary Medicine, University of Cambridge, Queen's Veterinary School Hospital, Madingley Road, Cambridge, CB3 OES, UK Tel: +44 (0)1223 337621; Fax: +44 (0)1223 232977. E-mail:dlw33@cam.ac.uk

Received: 21 September 2016

Accepted: 22 September 2016

Published online:

11 November 2016 


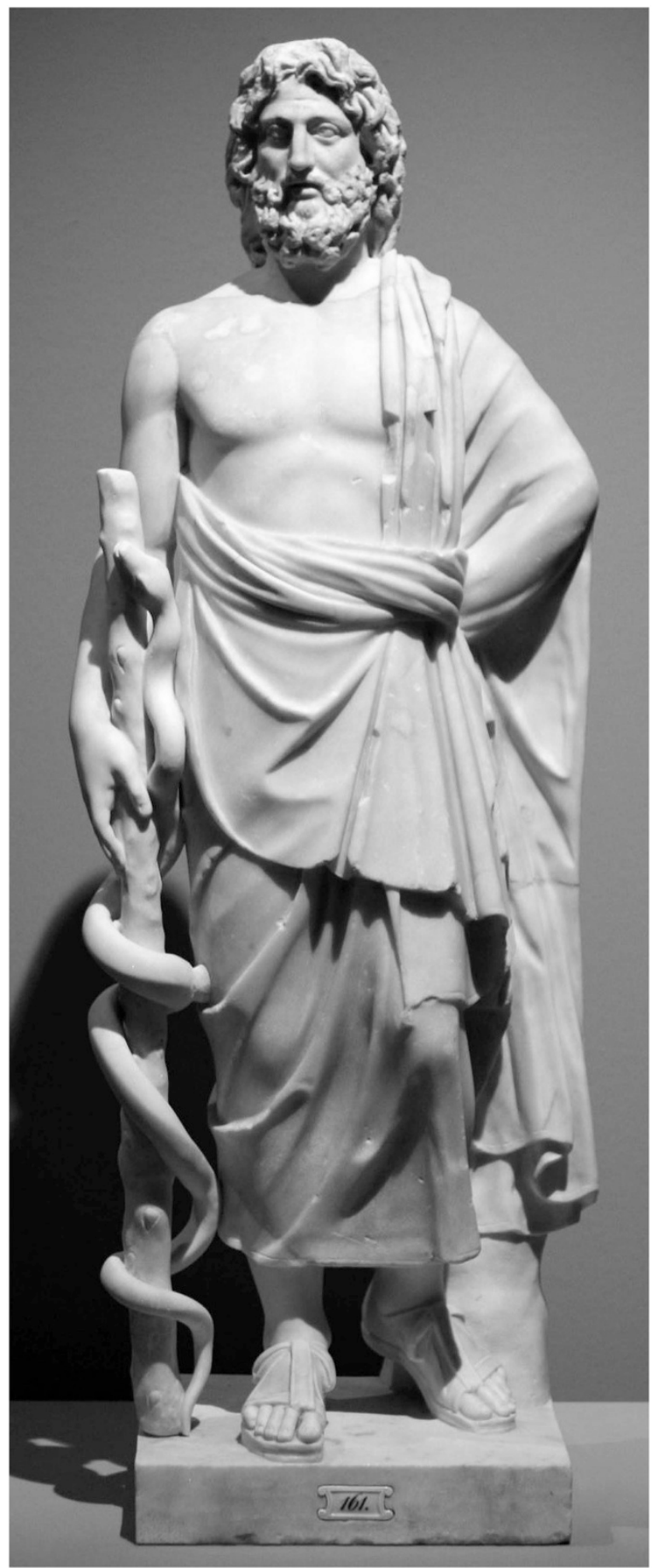

Figure 1 Asclepius and his rod with obligatory snake coiled around it.

\section{Tissue regeneration in lower vertebrates}

Lower vertebrates, that is to say fish, amphibians, and reptiles, generally grow throughout life, not reaching a maximal adult size as do the high vertebrate birds and mammals. And generally in association with this, they have also maintained the ability to regenerate,
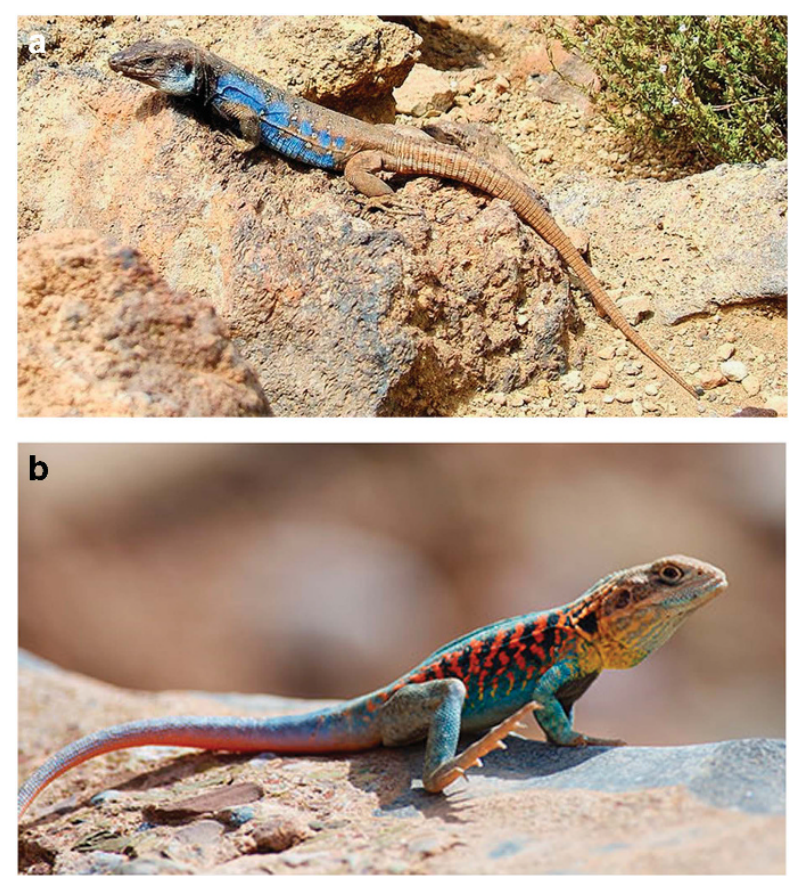

Figure 2 (a) The Gallotia galloti the Tenerife wall lizard. (b) Ctenophorus ornatus the ornate dragon lizard.

be it the regrowth of the lizard tail after autotomy, ${ }^{3,4}$ limb regeneration in amphibia, ${ }^{5}$ cardiac regrowth in fish $^{6}$ and, of more interest in this paper, lens and retinal replication in newts ${ }^{7}$ and fish. ${ }^{8}$ In truth, the involvement of reptiles in the alliterative title of this paper does leave us with somewhat of a problem, since the retinal ganglion cell (henceforth RGC) regeneration involved in neural regrowth after optic nerve injury (ONI) as either a crush episode or frank axonotomy is not as complete as in the piscine or amphibian examples we will cover later. Nevertheless, the variation in RGC regeneration between reptile species may give opportunities to study what molecular and cellular mechanisms are at work in RGC development and redevelopment.

\section{Retinal ganglion cell regeneration in reptiles}

The wall lizard Gallotia galloti (Figure 2a) is found on the Canary Islands and the striking colour of the males suggests the importance of vision for mate choice in this species. In fact it is more likely to be the markings, which reflect electromagnetic radiation in the ultraviolet spectrum that are most important in sexual selection. ${ }^{9}$ Indeed across reptile genera, as with avian vision photoreceptor sensitivity in the ultraviolet is very important. ${ }^{10,11}$ Never let us think that as trichomats we are at some evolutionary pinnacle in visual development! Although we might admire the wide variation in 
colouration of the ornate crevice dragon lizard Ctenophorus ornatus ${ }^{12}$ vision in the ultraviolet spectrum is again crucial to this species too. ${ }^{13}$

But where the Gallotia and Ctenophorus lizards may be similar in their use of ultraviolet signalling, their response to optic nerve axonotomy is surprisingly different.

Perhaps the first thing to say is that both lizards, as with all reptiles, show a considerable survival of RGC after ONI. In birds and mammals, degeneration of RGC after axonal injury is widespread as first recognised by Santiago Ramon y Cajal as long ago as $1928 .{ }^{14}$ Axons start to sprout at the site of the injury in these higher vertebrates, but degenerate within a week and are lost with apoptosis of the RGC cell body. After a standard optic nerve crush injury in the Gallotia and Ctenophorus lizards, however, axon regeneration occurs even in the face of a glial scar and the absence of proliferating cells in the retina itself. But although the Gallotia lizard has an average RGC loss of around 30\% and slow regeneration over 6 months or so with $60 \%$ of neurectomised animals regaining a pupillary light reflex, ${ }^{15}$ Ctenophorus has a significantly better axonal regeneration with an accelerated time course compared with Gallotia. Its axons reach the visual centres of the brain within a month. Although this sounds impressive, functionality depends on correct topographic localisation of migrating neurons and here even Ctenophorus falls short of our expectations. Although all seems well to start with post injuiry and pupillary light reflexes are restored at $2-3$ months post injury, the topographic arrangement of the retinal projections is not maintained in the regenerating optic nerve. Vision allowing such essential behaviours as accurate apprehension of prey items is not regained after ONI, nor are the retinotectal projections in these lizards stable. Regenerating axons seem to be continually searching, as it were, for the correct projection rather than forming robust synaptic connections as shown anatomically ${ }^{16,17}$ or electrophysiologically. ${ }^{18}$ And so perhaps now is the time to stray a bit further back in evolution and consider the anamniotes, amphibians, and fish and their responses to optic nerve damage as opposed to the poorer regenerative capacity of the amniotes, those vertebrates developing in an egg with an amnion.

\section{Different animals, different questions?}

Maybe as well as looking at the wrong genera, reptiles rather than amphibians and fish, perhaps we are asking the wrong question in trying to define what causes optic nerve regeneration in animals where it occurs. Maybe we should be asking what prevents RGC regeneration in higher species. Is it the nerve itself unable to survive and experience renewal or is it the environment of the damaged nerve, which is key in preventing nerve regeneration? Do amphibia and fish have RGC, which themselves are intrinsically more able to regenerate or is it the environment of the ONI scar, which is the key variable? At a more fundamental level, is it merely RGC survival that explains the restoration of visual processes after ONI or is optic nerve regeneration more related to de novo RGC neurogenesis? It used to be thought that the retinae of anamniote species continually produced new neurons and that this accounted for restoration of the optic nerve. In fish, retinal stem cells do continually give rise to new RGC. However, studies on adult Xenopus, the African clawed toad, showed that in these animals neurogenesis in the retina ceased once adulthood has been reached. ${ }^{19}$ Even so, RGC axons regenerate in adult Xenopus. ${ }^{20}$ In fish, on the other hand, retinal neurogenesis occurs throughout life with stem cells present and continually proliferating. ${ }^{21}$ Before we get too excited about this as a critical difference between fish and mammals, it has to be remembered that the central nervous system of every genera seems to have latent stem cells, ${ }^{22,23}$ which might be able to give rise to new nerve cells in the right circumstances, though much more promisingly in lower vertebrates.

It was back in 1927 that Matthey reported optic nerve regeneration in amphibia ${ }^{24}$ but not until more than 20 years later that Sperry documented the same results in fish. ${ }^{25}$ With regard to RGC survival, we know, as noted above, that after ONI in the rat the RGC undergo apoptosis within 3-5 days post injury. Terminal deoxynucleotidyl transferase-mediated dUTP nick end labelling staining demonstrates apoptotic signals in the rat retina 7 days after $\mathrm{ONI}^{26}$ whereas in the fish no such signals are seen at any time point after axonotomy. ${ }^{27}$ What accounts for this RGC survival? Presence of proand anti-apoptotic factors differ substantially between piscine and mammalian RGC post ONI. Phospho-Akt and phosphor-Bad are anti-apoptotic molecules from the phosphatidylinositol-3-kinase system, which increase after ONI in the fish ${ }^{28}$ but decrease in the rat. ${ }^{29}$ Insulinlike growth factor-1 and brain-derived neurotrophic factor are both key activators in the phosphatidylinositol3-kinase system and levels of IGF-12 increase in the goldfish after ONI but rapidly decrease in the rat. ${ }^{27}$ Heat shock proteins (HSP) also seem key in RGC survival. HSP are chaperon molecules protecting cells from a wide variety of environmental and physiological insults. HSP70 mRNA increases over theefold in the first few hours after ONI in the zebra fish but not after mammalian ONI. ${ }^{30}$ Here inhibition of HSP activity blocked expression of the anti-apoptotic protein Bcl-2 and increased levels of the apoptotic protein Bax.

Is there a central trigger factor behind these various changes? Purpurin, a retinol blinding protein, increases 
markedly but transiently in the fish retina after ONI suggesting that retinoid activity may have an important role in recovery after ONI, acting as a molecular signalling cascade. ${ }^{31}$ Is the same true in other species? Retinoic acid signalling is also upregulated in the frog after $\mathrm{ONI}^{32}$ and while there is normally no regeneration after ONI in mammals, a model using the neuroprotective herbal iridoid genipin does allow RGC regeneration. Inhibition of retinoic acid receptor beta expression by use of siRNA inhibits the neuritogenic actions of IPRG001, a genipin derivative. ${ }^{33}$

\section{Ganglion cell growth or scar permissivity?}

We have said that on the one hand, there are intrinsic factors in the anamniote RGC, which explain their survival and regeneration but on the other, the extracellular environment after the ONI is critical too. The glial scar resulting from the ONI in mammals is inhibitory to nerve regeneration. Oligodendrocytes and myelin are potent inhibitors of axonal regrowth in the mammalian central nervous system, ${ }^{34}$ but in the fish and amphibian this regrowth is not inhibited in the same manner with oligodendrocytes successfully remyelinating regenerating optic nerve axons, ${ }^{35}$ which can then reform synapses in the optic tectum. ${ }^{36}$ The area of ONI in fish is characterised by increased extracellular matrix molecules, such as tenascin, chondroitin sulphate, and laminin. ${ }^{37,38}$ If we return to the lizards we began with, straddling the gap between the axonal restoration of the fish and the failure of regeneration in mammals, RGC axons in Gallotia galloti regenerate successfully even in the presence of inhibitory myelin and oligodendrocytes. Their sensitivity seems to be less than neurons from higher vertebrates. Intricate work from Lang and Stuermer's group culturing Gallotia retinal explants on lizard or rat glial cell cultures or rat dorsal root ganglion explants on lizard optic nerve explants showed that lizard RGC growth cones traversed rat oligodendrocyte cultures, whereas rat neurons are inhibited by lizard oligodendrocytes. ${ }^{39}$ It seems that it may be the lizard RGC which has the ability to regenerate in whatever environment it is placed. Perhaps it is its response to signals that go unnoticed by mammalian RGC is the key factor in its survival and regeneration. Hypertrophic gliosis in the region of ONI (Figure 3) is mediated by axons in the locality with the presence of growing optic nerve fibres being essential to oligodendrocyte and type II astrocyte differentiation. ${ }^{40}$

\section{Mammalian relevance?}

Although the work on fish, amphibians, and reptile ONI is fascinating, its true relevance must be in what it tells us about repair of mammalian optic nerves and, though it

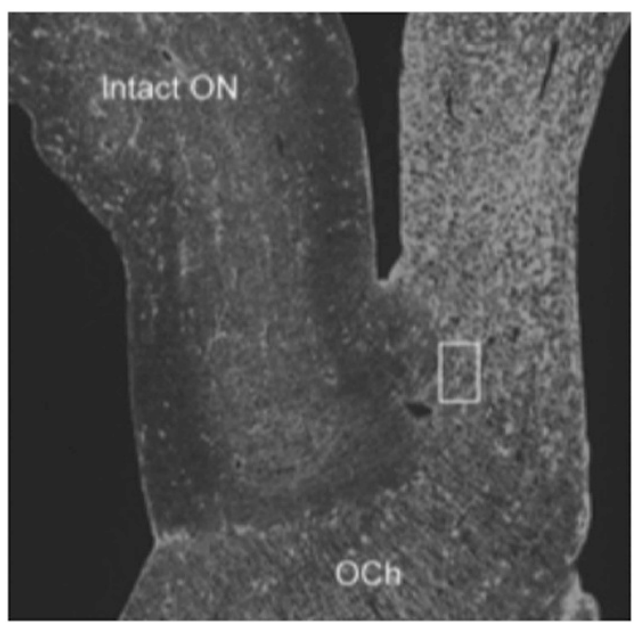

Figure 3 GFAP staining shows astrocytosis in injured optic nerve (right).

pains me as a veterinary surgeon to have to say this, its impact really lies on how it can help us in understanding restoration of human optic nerve structure and function not regaining lizard or fish vision! As we move to recovery from ONI in fish to mammals perhaps we can move to an animal which, while clearly a mammal, has optic nerve regeneration much more similar to that in fish and amphibians. This is the naked mole rat (Heterocephalus glaber). ${ }^{41}$ Little bigger than a standard laboratory mouse (Mus musculus), the naked mole rat has a lifespan not of 2-3 years as with $M u s$ but rather of 30 years. Living underground with low-oxygen levels in large eusocial colonies, Heterocephalus is nye on poikilothermic, living with its body temperature matching the ambient temperature. These animals not only has an exceptionally long lifespan but little in the way of senescence and rare reports of neoplasia. Its cells have high levels of telomerase, which may explain the substantial longevity but also ironically high levels of oxidative stress. ${ }^{42}$ So with all these unusual characteristics perhaps it is not surprising that the naked mole rat's response to $\mathrm{ONI}$ is very different from those in more conventional mammals. Rather than the low percentage of RGCs that survive ONI in other mammals, in Heterocephalus, $70 \%$ of RGC survive ONI and three times more optic nerve axons show regeneration after ONI. So what differs between conventional laboratory rodents and Heterocephalus with regard to the damaged optic nerve? The JAK/STAT pathway seems to play an important part in optic nerve regeneration in fish ${ }^{43}$ and, while there is nearly no optic nerve p-STAT3 immunoreactivity in Mus, many RGC in Heterocephalus express nuclear p-STAT3 after ONI. Not only are there intrinsic differences in Heterocephalus RGC but extrinsic 


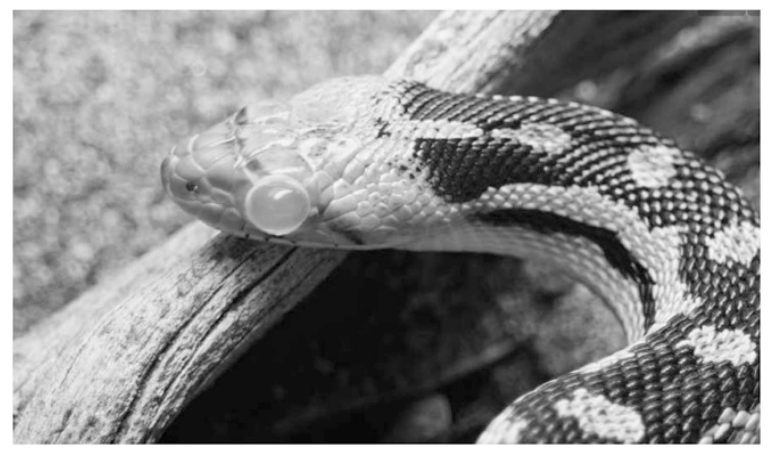

Figure 4 Boa constrictor with an apparently buphthalmic glaucomatous globe but actually with a bullous spectaculopathy.

variations may be critical, particularly those in astrocytes. Immunohistochemistry for GFAP, a marker for reactive astrocytes shows little difference between Heterocephalus and Mus optic nerves 3 days after ONI, whereas at 14 days, there is little GFAP immunoreactivity in Mus but intense staining in Heterocephalus. ${ }^{44}$ In most mammals, the fibrotic scars after ONI tend to preclude the formation of glial bridges across the lesion, whereas in fish, amphibians, and naked mole rats astrocyte involvement in the regenerating optic nerve seems to be key.

Astrocytes have key roles in remodelling the optic nerve scar, but their activity and neuronal responses to it differ substantially between species.

\section{Conclusion}

The reason for being concerned about RGC regeneration after ONI is of course to prevent the sight threatening damage of glaucoma. So perhaps rather than looking at experimental optic nerve crush models, we should be searching for spontaneously glaucomatous reptiles. Cases such as that in Figure 4 appear exactly what we are looking for-an animal with an enlarged glaucomatous globe. But here we need to go back to Pliny the Elder with whom we started. The apparent rejuvenation experienced by the snakes he saw was in fact shedding of the skin and transparent spectacle. And the swelling seen in Figure 4 is not an enlarged globe but rather a swollen spectacle in an animal with an occluded nasolacrimal duct, in what we term a bullous spectaculopathy. ${ }^{45}$ All of which goes to show how difficult it can be to extrapolate from these findings in species very different from the experimental laboratory mammals we are more used to investigating. Part of the fascination of investigating responses to ONI in these lower vertebrates is quite how different they are, how ready they are to regenerate. They are so different, however, in so many varying ways that it can be very difficult to determine what it is, RGC or scar biology or both, which accounts for this dramatic variation in RGC regeneration in these lower vertebrates compared with the vast majority of mammals.

\section{Conflict of interest}

The author declares no conflict of interest.

\section{References}

1 Antoniou SA, Antoniou GA, Learney R, Granderath FA, Antoniou AI. The rod and the serpent: history's ultimate healing symbol. World J Surg 2011; 35(1): 217-221.

2 Pliny the Elder. Naturalis Historia 8: 41. Available at: http:// www.perseus.tufts.edu/hopper/text?doc=Plin.+Nat.+toc.

3 Alibardi L. Histochemical, biochemical and cell biological aspects of tail regeneration in lizard, an amniote model for studies on tissue regeneration. Prog Histochem Cytochem 2014; 48(4): 143-244.

4 Gilbert EA, Payne SL, Vickaryous MK. The anatomy and histology of caudal autotomy and regeneration in lizards. Physiol Biochem Zool 2013; 86(6): 631-644.

5 Kusumi K, Fisher RE. Studying mechanisms of regeneration in amphibian and reptilian vertebrate models. Anat Rec (Hoboken) 2012; 295(10): 1529-1531.

6 Gamperl AK, Farrell AP. Cardiac plasticity in fishes: environmental influences and intraspecific differences. J Exp Biol 2004; 207(Pt 15): 2539-2550.

7 Del Rio-Tsonis K, Tsonis PA. Eye regeneration at the molecular age. Dev Dyn 2003; 226(2): 211-224.

8 Pushchina EV, Shukla S, Varaksin AA, Obukhov DK. Cell proliferation and apoptosis in optic nerve and brain integration centers of adult trout Oncorhynchus mykiss after optic nerve injury. Neural Regen Res 2016; 11(4): 578-590.

9 Thorpe RS, Richard M Evidence that ultraviolet markings are associated with patterns of molecular gene flow. Proc Natl Acad Sci USA 2001; 98(7): 3929-3934.

10 Pérez i de Lanuza G, Font E. Ultraviolet vision in lacertid lizards: evidence from retinal structure, eye transmittance, SWS1 visual pigment genes and behaviour. J Exp Biol 2014; 217(Pt 16): 2899-2909.

11 Martin M, Le Galliard JF, Meylan S, Loew ER. The importance of ultraviolet and near-infrared sensitivity for visual discrimination in two species of lacertid lizards. J Exp Biol. 2015; 218(Pt 3): 458-465.

12 Stuart-Fox DM, Moussalli A, Johnston GR, Owens IP. Evolution of color variation in dragon lizards: quantitative tests of the role of crypsis and local adaptation. Evolution 2004; 58(7): 1549-1559.

13 Barbour HR, Archer MA, Hart NS, Thomas N, Dunlop SA, Beazley LD et al. Retinal characteristics of the ornate dragon lizard, Ctenophorus ornatus. J Comp Neurol 2002; 450(4): 334-344.

14 Ramon y Cajal S. Degeneration and Regeneration of the Nervous System. Translated by RM May. Oxford Scholarship Online 2012; available at doi:10.1093/acprof: oso/9780195065169.001.0001.

15 Santos E, Romero-Alemán MM, Monzón-Mayor M, Yanes C. Variable functional recovery and minor cell loss in the ganglion cell layer of the lizard Gallotia galloti after optic nerve axotomy. Exp Eye Res 2014; 118: 89-99. 
16 Dunlop SA, Tran N, Tee LB, Papadimitriou J, Beazley LD. Retinal projections throughout optic nerve regeneration in the ornate dragon lizard, Ctenophorus ornatus. J Comp Neurol 2000; 416(2): 188-200.

17 Beazley LD, Sheard PW, Tennant M, Starac D, Dunlop SA. Optic nerve regenerates but does not restore topographic projections in the lizard Ctenophorus ornatus. J Comp Neurol 1997; 377(1): 105-120.

18 Stirling RV, Dunlop SA, Beazley LD. Electrophysiological evidence for transient topographic organization of retinotectal projections during optic nerve regeneration in the lizard, Ctenophorus ornatus. Vis Neurosci 1999; 16(4): 681-693.

19 Grant S, Keating MJ. Ocular migration and the metamorphic and postmetamorphic maturation of the retinotectal system in Xenopus laevis: an autoradiographic and morphometric study. J Embryol Exp Morphol 1986; 92: 43-69.

20 Taylor JSH, Jack JL, Easter SS. Is the capacity for optic nerve regeneration related to continued retinal ganglion cell production in the frog?. Eur J Neurosci 1989; 1(6): 626-638.

21 Perron M, Harris WA. Retinal stem cells in vertebrates bioessays. Bioessays 2000; 22(8): 685-688.

22 Alunni A, Bally-Cuif L. A comparative view of regenerative neurogenesis in vertebrates. Development 2016; 143(5): 741-753.

23 Taupin P, Gage FH. Adult neurogenesis and neural stem cells of the central nervous system in mammals. J Neurosci Res 2002; 69(6): 745-749.

24 Matthey R. Recuperation de la vue apres resection des nerfs optiques chez le triton. CR Soc Biol 1925; 93: 904-906.

25 Sperry RW. Patterning of central synapses in regeneration of the optic nerve in teleosts. Physiol Zool 1948; 21(4): 351-361.

26 Bien A, Seidenbecher CI, Böckers TM, Sabel BA, Kreutz MR. Apoptotic versus necrotic characteristics of retinal ganglion cell death after partial optic nerve injury. J Neurotrauma 1999; 16(2): 153-163.

27 Koriyama Y, Homma K, Sugitani K, Higuchi Y, Matsukawa T, Murayama D et al. Upregulation of IGF-I in the goldfish retinal ganglion cells during the early stage of optic nerve regeneration. Neurochem Int 2007; 50(5): 749-756.

28 Koriyama Y, Homma K, Kato S. Activation of cell survival signals in the goldfish retinal ganglion cells after optic nerve injury. Adv Exp Med Biol 2006; 572: 333-337.

29 Homma K, Koriyama Y, Mawatari K, Higuchi Y, Kosaka J, Kato S. Early downregulation of IGF-I decides the fate of rat retinal ganglion cells after optic nerve injury. Neurochem Int 2007; 50(5): 741-748.

30 Nagashima M, Fujikawa C, Mawatari K, Mori Y, Kato S. HSP70, the earliest-induced gene in the zebrafish retina during optic nerve regeneration: its role in cell survival. Neurochem Int 2011; 58(8): 888-895.
31 Kato S, Matsukawa T, Koriyama Y, Sugitani K, Ogai K. A molecular mechanism of optic nerve regeneration in fish: the retinoid signaling pathway. Prog Retin Eye Res 2013; 37: 13-30.

32 Duprey-Díaz MV, Blagburn JM, Blanco RE. Optic nerve injury upregulates retinoic acid signaling in the adult frog visual system. J Chem Neuroanat 2016; 77: 80-92.

33 Koriyama Y, Takagi Y, Chiba K, Yamazaki M, Sugitani K, Arai $\mathrm{K}$ et al. Requirement of retinoic acid receptor $\beta$ for genipin derivative-induced optic nerve regeneration in adult rat retina. PLoS One 2013; 8(8): e71252.

34 Caroni P, Schwab ME. Oligodendrocyte- and myelinassociated inhibitors of neurite growth in the adult nervous system. Adv Neurol 1993; 61: 175-179.

35 Wolburg H. Myelination and remyelination in the regenerating visual system of the goldfish. Exp Brain Res 1981; 43(2): 199-206.

36 Stuermer CA, Easter SS Jr. A comparison of the normal and regenerated retinotectal pathways of goldfish. J Comp Neurol 1984; 223(1): 57-76.

37 Becker CG, Schweitzer J, Feldner J, Schachner M, Becker T. Tenascin- $R$ as a repellent guidance molecule for newly growing and regenerating optic axons in adult zebrafish. Mol Cell Neurosci 2004; 26(3): 376-389.

38 Becker CG, Becker T. Repellent guidance of regenerating optic axons by chondroitin sulfate glycosaminoglycans in zebrafish. J Neurosci 2002; 22(3): 842-853.

39 Lang DM, Monzón-Mayor M, Bandtlow CE, Stuermer CA. Retinal axon regeneration in the lizard Gallotia galloti in the presence of CNS myelin and oligodendrocytes. Glia 1998; 23 (1): 61-74.

40 Levine RL. Axon dependent glial changes during optic fiber regeneration in the goldfish. J Comp Neurol 1993; 333(4): 543-553.

41 Buffenstein $\mathrm{R}$. The naked mole-rat: a new long-living model for human aging research. J Gerontol A Biol Sci Med Sci 2005; 60(11): 1369-1377.

42 Andziak B, O'Connor TP, Qi W, DeWaal EM, Pierce A, Chaudhuri AR et al. High oxidative damage levels in the longest-living rodent, the naked mole-rat. Aging Cell 2006; 5 (6): 463-471.

43 Elsaeidi F, Bemben MA, Zhao XF, Goldman D. Jak/Stat signaling stimulates zebrafish optic nerve regeneration and overcomes the inhibitory actions of Socs3 and Sfpq. J Neurosci 2014; 34(7): 2632-2644.

44 Park KK, Luo X, Mooney SJ, Yungher BJ, Belin S, Wang C et al. Retinal ganglion cell survival and axon regeneration after optic nerve injury in naked mole-rats. J Comp Neurol 2016; epub ahead of print 28 June 2016; doi:10.1002/cne.24070.

45 Cullen CL, Wheler C, Grahn BH. Diagnostic ophthalmology. Bullous spectaculopathy in a king snake. Can Vet J 2000; 41(4): 327-328. 